\title{
EXPERIENCE ON THE TREATMENT OF ANORECTAL ABSCESSES WITH PRIMARY OR LIGATION FISTULOTOMY
}

\author{
Dimitar Hadzhiev', Dzhevdet Chakarov', Evgenii Moshekov², Boris Sakakushev', \\ Chavdar Atanasov ${ }^{1}$, Elena Hadzhieva ${ }^{1}$, Ivan Ivanov ${ }^{1}$, Kostadin Kandilarov ${ }^{1}$, \\ Bozhidar Hadzhiev ${ }^{1}$
}

${ }^{1}$ Department of General Surgery, First Clinic of Surgery, St. George University Hospital,

${ }^{2}$ Pediatric Surgery Clinic, Faculty of Medicine, Medical University, Plovdiv, Bulgaria

\begin{abstract}
INTRODUCTION: Anorectal abscess (ARA) is frequently treated inappropriately with a simple incision and drainage. In $30-50 \%$ of the patients this leads to recurrent ARA, chronic rectal fistula and several hospital admissions.

PATIENTS AND METHODS: For a ten years period, from 2007 till 2016, 547 patients with ARA were operated. Males were 419 and females 128, with a ratio of 3.3:1. Depending on localization, we divide four types of ARA: perianal - 281 patients (51.4\%), ischiorectal - 176 patients (32.2\%), intersphincteric - 56 patients $(10.2 \%)$, supralevator -34 patients $(6.2 \%)$.

RESULTS: Radical operative treatment of ARA depends of type and location of abscess, its relationship to the sphincter and the extent of the inflammatory process. In 204 patients (37.3\%) was performed incision, revision and drainage. In perianal, lower types of intersphincteric ARA incision, revision, excision of the fistula and the crypt is performed. This kind of operation we carried out on 181 patients (33.1\%). In all ischiorectal, high intersphincteric and supralevator ARA we made wide incision, digital revision, necrectomy, drainage and seton ligation for gradual and continuous section of the sphincter, performed on 162 patients (29.6\%).

CONCLUSIONS: Surgical tactics based on individual and differentiated approach of ARA treatment in specialized coloproctologic clinics assures effective and radical management, avoiding secondary abscess or chronic fistulization. Although still on debate, the primary or ligation fistulotomy should become a method of choice for the radical treatment of ARA, eliminating the possibility of recurrent inflammation or fistula-in-ano. Scr Sci Med 2017; 49(3): 45-48
\end{abstract}

Keywords: anal abscess, anorectal abscess, fistula-in-ano, fistulotomy

\footnotetext{
Address for correspondence:

Prof. Dimitar Hadzhiev, MD, PhD

Department of General Surgery

First Clinic of Surgery

St. Georgi University Hospital of Plovdiv

Plovdiv, 4000

Bulgaria

$15 a$ Vasil Aprilov Blvd.

e-mail:hadzhievd@yahoo.com
}

Received: July 31, 2017

Accepted: September 15, 2017

\section{INTRODUCTION}

Anorectal suppurations still actually matter, despite the progress of modern surgery. This is mainly due to unqualified surgical intervention, leading to recurrent inflammation and hospital readmission. Anorectal abscess (ARA) is common urgent proctologic disease, comprising $25 \%$ of all rectal diseases, with a $0.5 \%$ population occurrence. The simple incision and drainage seldom leads to healing, because of the secondary infections and fistula-in-ano, due to 
persistent internal opening between the rectum and the surrounding tissues $(1,2)$. ARA starts with inflammation of the anal glands, which communicate with the cryptae of Morgagni (Fig. 1).

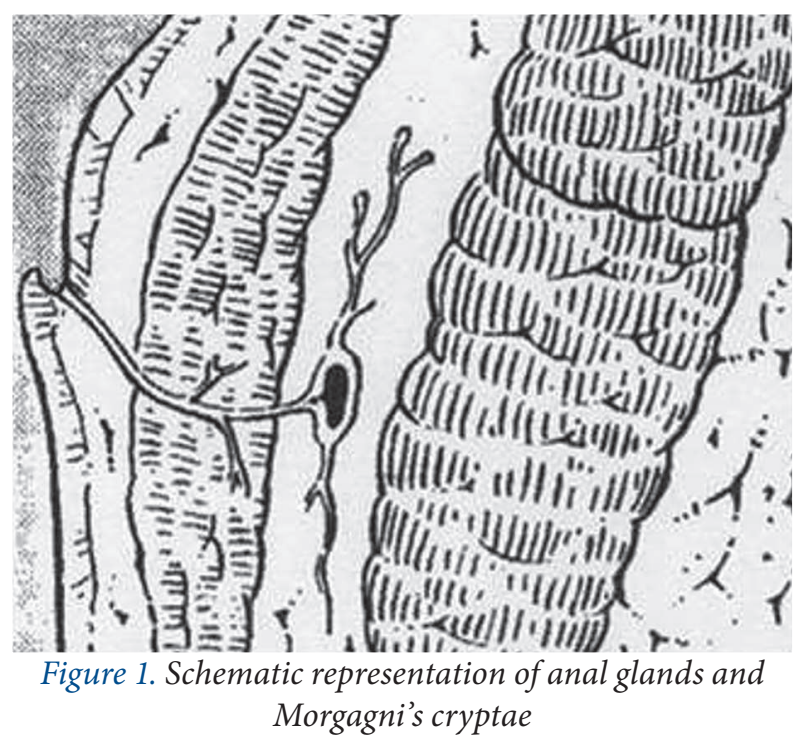

Their channel obstruction leads to suppuration - i.e. - cryptoglandular abscess. The crypts are situated on the dentate line in the anal canal, being the inner entrance of the abscess $(3,4)$. This cryptoglandular concept of the origin of anorectal abscesses and fistulas, surely unites them, which makes many authors consider them as different clinical entity of one and the same disease $(5,6)$.

The surgical tactic and approach to ARA is still under discussion, depending mainly on the possibilities and surgical experience, type and stage of the disease (7).

Nowadays in most cases the operative treatment of ARA is performed by non-experienced and young surgeons in general surgical wards, where they rarely pursuit onestage, efficient and radical treatment $(8$, 9). In $2 / 3$ of the cases, the absence of liquidation of the internal opening, leads to recurrent suppuration and fistula formation $(3,10-12)$.

\section{PATIENTS AND METHODS}

In the period 2007 - 2016, 547 patients with ARA have been operated on in our clinic. Men have been 419 , women - 128, with proportion 3.3:1. Mean age has been 46.1 (11 86 years). The age between 35 and 48 years is most common. The time of onset of the disease till admission varies from 2 to 9 days (mean 4.2 days).

As illustrated in Figure 2, according to the localization ARA are divided into:

1. Perianal in 281 patients - $51.4 \%$

2. Ischiorectal in 176 patients - $32.2 \%$

3. Intersphincteric in 56 patients - $10.2 \%$

4. Supralevator in 34 patients - $6.2 \%$

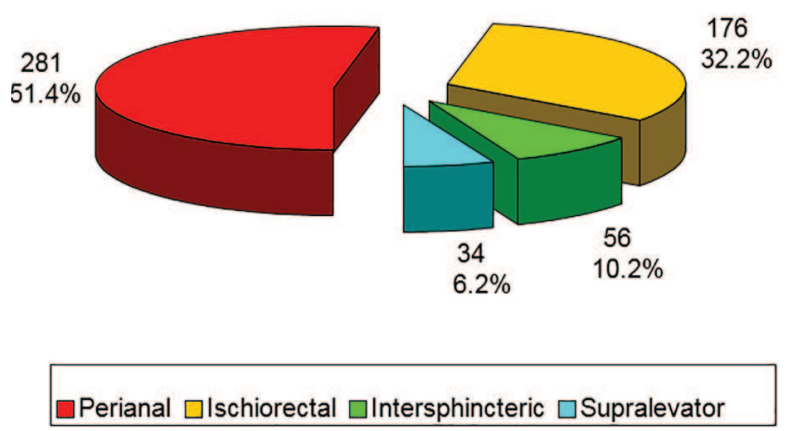

Figure 2. Distribution of anorectal abscess by localization

In all of the patients surgical treatment was urgent. Short preoperative preparation has been applied in cases with concomitant diseases, advanced age and progressive disease with intoxication. Operations have been done under general anesthesia without colon preparation.

\section{RESULTS AND DISCUSSION}

The radical and successive treatment of ARA depends on localization, stage and course of the disease, relation of the fistula canal to the sphincters and surgeon's experience. Basic principle of ARA treatment is wide opening and drainage of the abscess, liquidation of the internal opening of the abscess, connecting its cavity with the rectum, preserving the integrity of the outer anal sphincter.

Surgical management of ARA mainly depends on type and topography of the inflammation process. In every case superficial elliptical skin excision is performed, followed by wide incision in depth, digital revision, uniting the separate hollows, necrosectomy, antiseptic management of the abscess cavity, discovering and treatment of the internal opening. The incision is semilunar or radial to the anal channel, close to him, assuring good opening of the wound and satisfactory drainage of debris. In $204 \mathrm{pa}-$ 
tients (37.3\%) was performed incision, revision and drainage.

The identification of the internal opening is very important for the one stage radical treatment of ARA. We have succeeded to do this in 343 patients (62.7\%). In non-complicated cases a digit into rectum is very helpful. In difficult cases precise localization of the inner entrance is obtained by dying (methilen blue) or hydrogen peroxide, which goes parallelly with anoscopy. Goodsall's law makes this act easier.

The type of fistulotomy (primary and complete or partial and ligature) depends on the relation of fistula channel to the internal opening, according to muscle fibers of the sphincter $(13,14)$.

In superficial ARA (subcutaneous, submucosal, some low types intersphincteric abscess) in the presence of intra- or transsphinceric fistula channel going through less of $1 / 3$ of outer muscular fibers of the external anal sphincter a leaf excision is made, followed by revision and excision of the whole fistula channel together with the crypt - i.e. a primary fistulotomy with cryptectomy is performed. It was done in 181 patients (33.1\%), where fistula channel below the dentate line was found. In superficial anorectal abscess there is always intra- or transsphincteric communication from the abscess to the internal opening of the rectum. The wound after the complete fistula channel excision is left open and treated with antibiotic liniment bandage.

In deep ARA (ischiorectal, high intersphincteric and supralevator abscess (Fig. 3), where extrasphincteric or suprasphincteric fistula channel is to be found, we have used wide semilunar incision, digital revision, necrosectomy, drainage situation, complete excision of fistula channel to the sphincter, with contemporary application of seton ligation for gradual section of the sphincter. This kind of ligation fistulotomy by seton in the deep abscess has been applied in 162 patients (29.6\%) (Fig. 4).

The excision of the fistula channel is done with the help of bland probe, going through the abscess and internal opening of the rectum. After two or three tightening in every four days the ligature gradually cuts the sphincter and falls down. It's very important for the ligature to be placed exactly through the internal opening of the rectum, which is always situated in the region of Morganian's crypts.

\section{PROFOUND ANORECTAL ABSCESS}
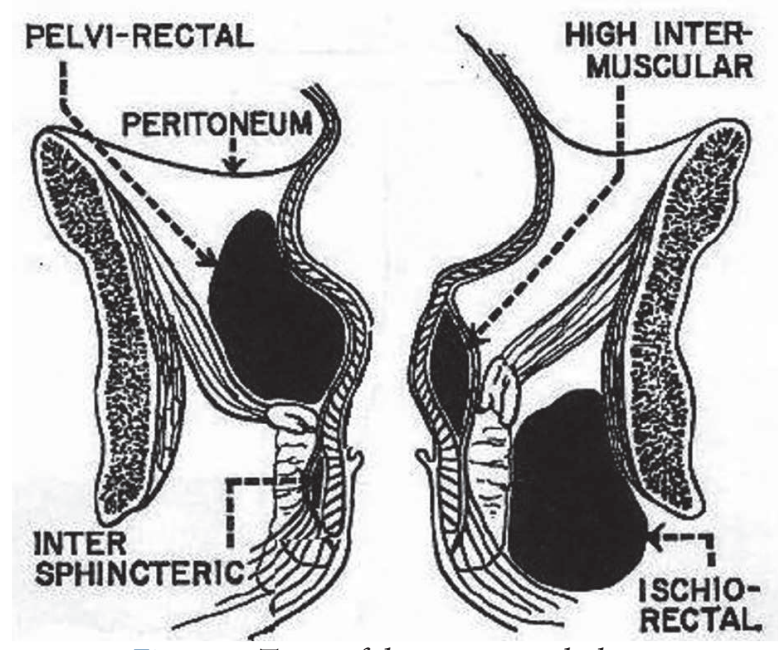

Figure 3. Types of deep anorectal abscess

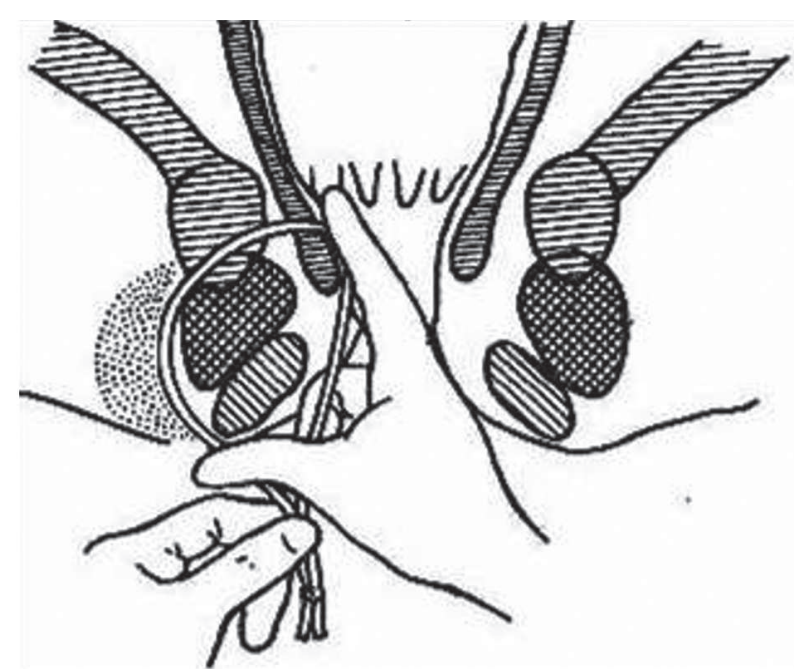

Figure 4. Ligation fistulotomy by seton in the deep abscess

In the deep ARA, as a rule, except the rubber ligature, we always apply drainage in the deepest part of the abscess cavity. In the first 5-10 days, antiseptic lavage through the drain is performed.

The standard therapy of the practicing surgeons in the presence of abscess is the surgical drainage. In ARA there are specific peculiarities, difficult for the surgeon to deal with:

1. Sphincter apparatus and need for preserving the muscular fibers.

2. Communication of the abscess with the internal opening of the rectum.

3. Difficult localization of the deep abscess. 
4. In some cases is more rational the transrectal incision (submucosal ARA).

5. Obligatorily drainage through the shortest way.

6. Adequate incision for best debris drainage.

Complete healing of ARA patients is obtained on 20-30 day after radical operation.

\section{CONCLUSIONS}

The main reason for recurrent suppuration or anorectal fistula is the small, simple primary incision, performed by inexperienced surgeons, where the internal opening of the channel in the rectum is not treated. The choice of radical treatment depends on the localization, stage and type of ARA. The one stage radical operative treatment of ARA consists of wide opening of the abscess cavity and liquidation of internal opening in the rectum, by means of primary or ligation fistulotomy.

The one stage radical operation in ARA must be performed by an experienced surgeon-proctologist, which will to a greater extent avoid a following recurrence and fistula-in-ano formation.

\section{REFFERENCES}

1. Oliver I, Lacueva FJ, Pérez Vicente F, Arroyo A, Ferrer R, Cansado P, et al. Randomized clinical trial comparing simple drainage of anorectal abscess with and without fistula track treatment. Int J Colorectal Dis. 2003;18(2):107-10.

2. Ho YH, Tan M, Chui CH, Leong A, Eu KW, SeowChoen F. Randomized controlled trial of primary fistulotomy with drainage alone for perianal abscesses. Dis Colon Rectum. 1997;40(12):1435-8.

3. Seow-Choen F, Leong AF, Goh HS. Results of a policy of selective immediate fistulotomy for primary anal abscess. Aust N Z J Surg. 1993;63(6):485-9.

4. Cox SW, Senagore AJ, Luchtefeld MA, Mazier WP. Outcome after incision and drainage with fistulotomy for ischiorectal abscess. Am Surg. 1997;63(8):686-9.

5. Hämäläinen KP, Sainio AP. Incidence of fistulas after drainage of acute anorectal abscess. Dis Colon Rectum. 1998;41(11):1357-62.

6. Pigot $F$. Treatment of anal fistula and abscess. J Visc Surg. 2015;152(2 Suppl):S23-9. doi: 10.1016/j. jviscsurg.

7. Knoefel WT, Hosch SB, Hoyer B, Izbicki JR. The initial approach to anorectal abscesses: fistulotomy is safe and reduces the chance of recurrences. Dig Surg. 2000;17(3):274-8.

8. Wu CL. Experience on the treatment of acute anorectal abscess with primary fistulotomy. Gaoxiong Yi Xue Ke Xue Za Zhi. 1990;6(5):218-23 (in Chinese).

9. Malik A, Hall D, Devaney R, Sylvester H, Yalamarthi S. The impact of specialist experience in the surgical management of perianal abscesses. Int J Surg. 2011;9(6):475-7. doi: 10.1016/j.ijsu.2011.06.002.

10. 1Holzheimer RG, Siebeck M. Treatment procedures for anal fistulous cryptoglandular abscess - how to get the best results. Eur J Med Res. 2006;11(12):501-15.

11. 1Tang CL, Chew SP, Seow-Choen F. Prospective randomized trial of drainage alone vs. drainage and fistulotomy for acute perianal abscesses with proven internal opening. Dis Colon Rectum. 1996;39(12):1415-7.

12. 1Benjelloun EB, Jarrar A, El Rhazi K, Souiki T, Ousadden A, Ait Taleb K. Acute abscess with fistula: long-term results justify drainage and fistulotomy. Updates Surg. 2013;65(3):207-11. doi: 10.1007/ s13304-013-0218-z.

13. Schouten WR, van Vroonhoven TJ. Treatment of anorectal abscess with or without primary fistulectomy. Dis Colon Rectum. 1991;34(1):60-3.

14. Athanasiadis S., Fischbach N, Heumüller L, Marla B. Abscess excision and primary fistulectomy as initial therapy of peri-proctal abscess. Chirurg. 1990;61(1):53-8 (in German). 